\title{
Low-firing thick-film piezoresistive sensors for medical instruments
}

\author{
Thomas Maeder, Caroline Jacq, Peter Ryser \\ Laboratoire de Production Microtechnique (LPM), EPFL, Lausanne, Switzerland \\ *Tel.: +41-21-693-5823; fax: +41-21-693-3891; thomas.maeder@epfl.ch \\ Original version: Procedia Engineering 5 (Proc. Eurosensors XXIV, September 5-8, Linz, Austria), 1140-1143, 2010 \\ (C) 2010 Published by Elsevier Ltd; http://hdl.handle.net/10.1016/j.proeng.2010.09.312
}

\begin{abstract}
In this work, a low-firing thick-film materials system allowing fabrication of piezoresistive sensors on surgical alloys is presented in detail, with application to a force-sensing surgical instrument. The system comprises a series of individual thickfilm dielectric, conductor, resistive and overglaze compositions based on a lead borosilicate glass matrix. The moderate achieved firing temperature, around $625^{\circ} \mathrm{C}$, greatly increases compatibility with metallic substrates, allowing the use of high-strength medical alloys with low thermal degradation. Specific fillers for the dielectric layers increase adhesion on steel substrates and allow thermal matching to austenitic and ferritic / martensitic steels, as well as titanium alloys. The functionality of this materials system is successfully demonstrated here by implementing it into a previously developed ligament-balancing force sensor for total knee arthroplasty (TKA) [1].
\end{abstract}

Keywords: Medical operations; total knee arthroplasty; thick-film force sensors; medical alloys

\section{Introduction}

Smart surgical instruments including load-sensing technology and allowing feedback to the surgeon, robotic surgery and haptics lead to better repeatability [2], safety and success rate of surgical operations. In addition, load-sensing implants and various robotic devices may constitute a useful tool in monitoring patient recovery, aiding re-education and rehabilitation [3]. Compared to polymer-based devices, mineral thick-film sensing materials feature good structural and chemical stability, and allow hermetic packaging, which translates into stable implant behaviour and good sterilisability (autoclave or dry heat) for instruments. However, the high standard $850^{\circ} \mathrm{C}$ thick-film firing temperature is incompatible with high-strength metallic alloys, due to phase transitions, oxidation and annealing effects. This can be in part circumvented by the use of substrates such as solution-hardened high-nitrogen austenitic stainless steels [1], but these are very expensive to machine, and their high coefficient of thermal expansion (CTE) gives rise to problematic compressive stresses; in our first device intended to be fabricated with commercial thick-film materials only [1], a basic dielectric-conductor-resistor buildup (see Fig. 1a) was still possible, but the addition of crossovers (i.e. another dielectric-conductor sequence) inevitably led to delamination. This prompted the introduction of a lowstress crossover dielectric formulated with a low-melting glass. However, yield and reliability were still somewhat problematic due to the high compressive stresses in the main dielectric.

In order to solve these problems and allow the use of high-strength (and lower CTE) Ti alloys or martensitic steels, we endeavoured to develop a reliable thick-film materials system featuring low $\left(<650^{\circ} \mathrm{C}\right)$ firing temperature $[4,5]$ and adaptability to a large palette of alloys. A typical piezoresistive thick-film materials sequence, depicted on Fig. 1, mainly comprises dielectric, conductor and resistor materials with the optional addition of an "overglaze" glassy protection layer, and must optimise many aspects, such as CTE compatibility with the metallic substrate, adherence and chemical compatibility among layers in general and with the steel, strain-sensing properties of the resistors, while achieving good reliability, i.e. low process sensitivity, good reproducibility and long-term stability. This work reviews the development of a first-generation low-firing system for piezoresistive sensing on metallic substrates, and details its successful application to the TKA sensor.

\section{Low-firing thick-film materials}

\subsection{Glasses}

Except commercial compositions, all formulations in this study are based on the same two lead borosilicate glasses (V6 \& V8; data given in Table 1) used in our previous studies on low-firing dielectrics \& resistors [4-6]. They feature a high PbO content to obtain lower processing temperatures and an extra $2 \% \mathrm{Al}_{2} \mathrm{O}_{3}$ added to suppress crystallisation. For dielectrics or resistors, the ideal firing temperature lies ca. $100^{\circ} \mathrm{C}$ above the densification temperature of the glass alone, namely around $600^{\circ} \mathrm{C}$ for $\mathrm{V} 6$-based materials and around $500^{\circ} \mathrm{C}$ for V8-based ones. In this study, all dielectrics base on V6, with lower-melting V8 used for fritted conductors and overglazes. 


\subsection{Dielectric stack}

Given the aforementioned requirements, it appears rapidly (Fig. 1b) that the dielectric, which fulfills many functions, is by far the most critical and complex element; it makes chemical contact with all other layers, is responsible for the critical mechanical bonding to the steel and, as it is by far the most voluminous material, a good CTE matching is mandatory. These requirements may be partially conflicting and therefore problematic to fulfil with a single material. For instance, additives to improve adhesion and CTE matching may harm chemical compatibility with the resistor or even the insulating properties of the dielectric. However, these different functions may be carried out by different layers, as illustrated in Fig. 1b, indicated in Table 2 and detailed hereafter.



\begin{tabular}{|l|l|}
\hline Measuring bridge & Conductor \& resistor layers (+ overglaze) \\
\hline Dielectric 3 : compatibility & Chemical compatibility with conductors \& resistors \\
\hline Dielectric 2 : main layer & $\begin{array}{l}\text { Good CTE matching } \\
\text { Electrical insulation } \\
\text { Refire stability (no re-melting) }\end{array}$ \\
\hline Dielectric 1 : adhesion & Adhesion promoters + good CTE matching \\
\hline Substrate & Medical alloy - steel \\
\hline
\end{tabular}

Fig. 1. (a) typical thick-film stack; (b) dielectric buildup detailing the functions of the different layers.

Table 1. Composition of both glasses. Percentages refer to $\mathrm{PbO}+\mathrm{B}_{2} \mathrm{O}_{3}+\mathrm{SiO}_{2}$. Approximate densification temperature for 10 min at peak.

\begin{tabular}{|c|c|c|c|}
\hline Glass & & V6 & V8 \\
\hline $\mathrm{PbO}$ & [\%mass] & 75 & 85 \\
\hline $\mathrm{B}_{2} \mathrm{O}_{3}$ & {$[\%$ mass $]$} & 10 & 10 \\
\hline $\mathrm{SiO}_{2}$ & {$[\%$ mass $]$} & 15 & 5 \\
\hline $\mathrm{Al}_{2} \mathrm{O}_{3}$ addition & {$[\%$ mass $]$} & 2 & 2 \\
\hline Densification temperature (glass) & {$\left[{ }^{\circ} \mathrm{C}\right]$} & 500 & 400 \\
\hline CTE & {$[\mathrm{ppm} / \mathrm{K}]$} & $\approx 9.0$ & $\approx 10.5$ \\
\hline
\end{tabular}

Table 2. Dielectric multilayer buildup (all layers fired at $625^{\circ} \mathrm{C}$ ). $\dagger$ Cristobalite for austenitic steels (here) or quartz for ferritic $/$ martensitic.

\begin{tabular}{lccc}
\hline Layer (\# prints) & Thickness $[\mu \mathrm{m}]$ & Glass [\%vol.] & Filler [\%vol.] \\
\hline Crossover $(2 \mathrm{x})$ & 20 & $(=$ main) & $(=$ main $)$ \\
Compatibility $(1 \mathrm{x})$ & 20 & $50 \mathrm{~V} 6$ & $50 \mathrm{Al}_{2} \mathrm{O}_{3}$ \\
Main $(2 \mathrm{x})$ & 40 & $40 \mathrm{~V} 6$ & $60 \mathrm{SiO}_{2} \dagger$ \\
Adhesion $(1 \mathrm{x})$ & 17 & $75 \mathrm{~V} 6$ & $25 \mathrm{Fe}_{2} \mathrm{O}_{3}$ \\
\hline
\end{tabular}




\subsubsection{Adhesion layer}

Preliminary studies showed poor adhesion of basic filled-glass dielectrics to stainless steels, a situation only somewhat improved by prior oxidation of the substrate. This is thought to be due to oxygen depletion at the interface, which was countered by filling the first dielectric layer with $\mathrm{Fe}_{2} \mathrm{O}_{3}$, which provides a source of oxygen by partial reduction of $\mathrm{Fe}^{3+}$ to $\mathrm{Fe}^{2+}$. While we did not confirm its supposed mode of action, this solution was found to be an efficient adhesion promoter, failure nearly never occurring at the metal-dielectric interface [5].

\subsubsection{Main layer-CTE adjustment}

The CTE of this layer was adjusted by adding suitable fillers to the glass matrix, which provide mechanical stabilisation of the dielectric as well. This "main" dielectric composition was applied to crossovers as well. As fillers, we used quartz for the ferritic and martensitic stainless steels (CTE $\sim 11 \mathrm{ppm} / \mathrm{K}$ ), and cristobalite for the austenitic ones (CTE $\sim 17 \mathrm{ppm} / \mathrm{K}$ ).

\subsubsection{Chemical compatibility layer}

$\mathrm{SiO}_{2}$ (quartz \& cristobalite) fillers allow tuning of dielectric CTE, but tend to dissolve into the glass. As dissolution of the silica fillers into the high-lead V6 glass was found to lead to poor compatibility with both V6-based resistors and the commercial lowfiring resistive composition ESL 3114 (ElectroScience Laboratories, USA; thought to be based on a similar glass based on its materials safety data sheet), a chemical compatibility layer was introduced; it consists of V6 filled with alumina powder, which has poor CTE matching to the steel, but is more inert towards the resistor. For Ti alloys (CTE $\sim 8 \mathrm{ppm} / \mathrm{K}$ ), this composition can be also used as a main layer.

\subsection{Other layers}

Deposition of conductors and resistor layers followed the modified scheme developed in our previous study [5]. First, the solder pads and main conductive tracks are deposited and dried using a layer of commercial ESL $9912 \mathrm{Ag}$ conductor, which gives good adhesion and solderability but does not constitute a good resistor termination. Then, the first of two crossover dielectric layer (if required) is deposited and co-fired at $625^{\circ} \mathrm{C}$ with the $1^{\text {st }}$ conductor. After this, the $2^{\text {nd }}$ crossover dielectric layer is deposited and dried, followed by a commercial resistive composition, ESL $3114(10 \mathrm{k} \Omega)$ and again co-firing at $625^{\circ} \mathrm{C}$. For the resistor terminations, a custom conductor consisting of Ag powder ( $90 \% \mathrm{vol}$.) and V8 glass frit (10\% vol.) is printed and post-fired at $500^{\circ} \mathrm{C}$. This $2^{\text {nd }}$ conductor layer comprises the resistor terminations, acts as "reinforcement" for the solder pads and also as the "top" conductor for the crossovers. Finally, a protective overglaze of straight V8 glass is deposited and fired at $425^{\circ} \mathrm{C}$, ending the "high-temperature" processing steps, followed by a parylene coating to guard against possible leaching of lead from the glasses.

\section{Application to TKA ligament-balancing force sensor}

The steel mechanical structure of the sensor and testing jig / procedure were the same as before [1], with the new low-firing thick-film materials system replacing the mainly commercial materials, and the conductor layout modified to reflect the abovementioned new layer sequence (see 2.3). A picture of the resulting sensor is given in Fig. 2a, with the measurement results (force \& X position) for one plate shown in Fig. 2bc.

In line with our prior results $[4,5]$, good adhesion and reliability was observed for the new version of the TKA ligamentbalancing sensor (two sensing platforms, one for each condyle; each platform fitted with three force sensors allowing determination of total force and XY position). After calibration, testing at several positions (labelled efgh on Fig. 2bc) resulted in good matching between measured and applied total force (Fig. 2b), with a low position error for sufficiently large forces (Fig. 2c).

\section{Conclusions and outlook}

A complete low-firing thick-film materials system for ferritic / martensitic and austenitic steels was developed. The materials were formulated / selected to allow firing at $625^{\circ} \mathrm{C}$, which was found to be a good compromise between low processing temperature and good stability. This firing temperature allows application to high-strength steels, as it avoids problems with phase transitions and reduces softening due to annealing. Also, degradation by oxidation is considerably reduced, possibly leading in the future to application on titanium alloys as well. This new materials system was applied successfully to our previously developed ligament-balancing sensor for TKA, demonstrating its potential for fabrication of complex piezoresistive sensor cells. Finally, first results [7] indicate that achieving similar results for lead-free materials is possible. 

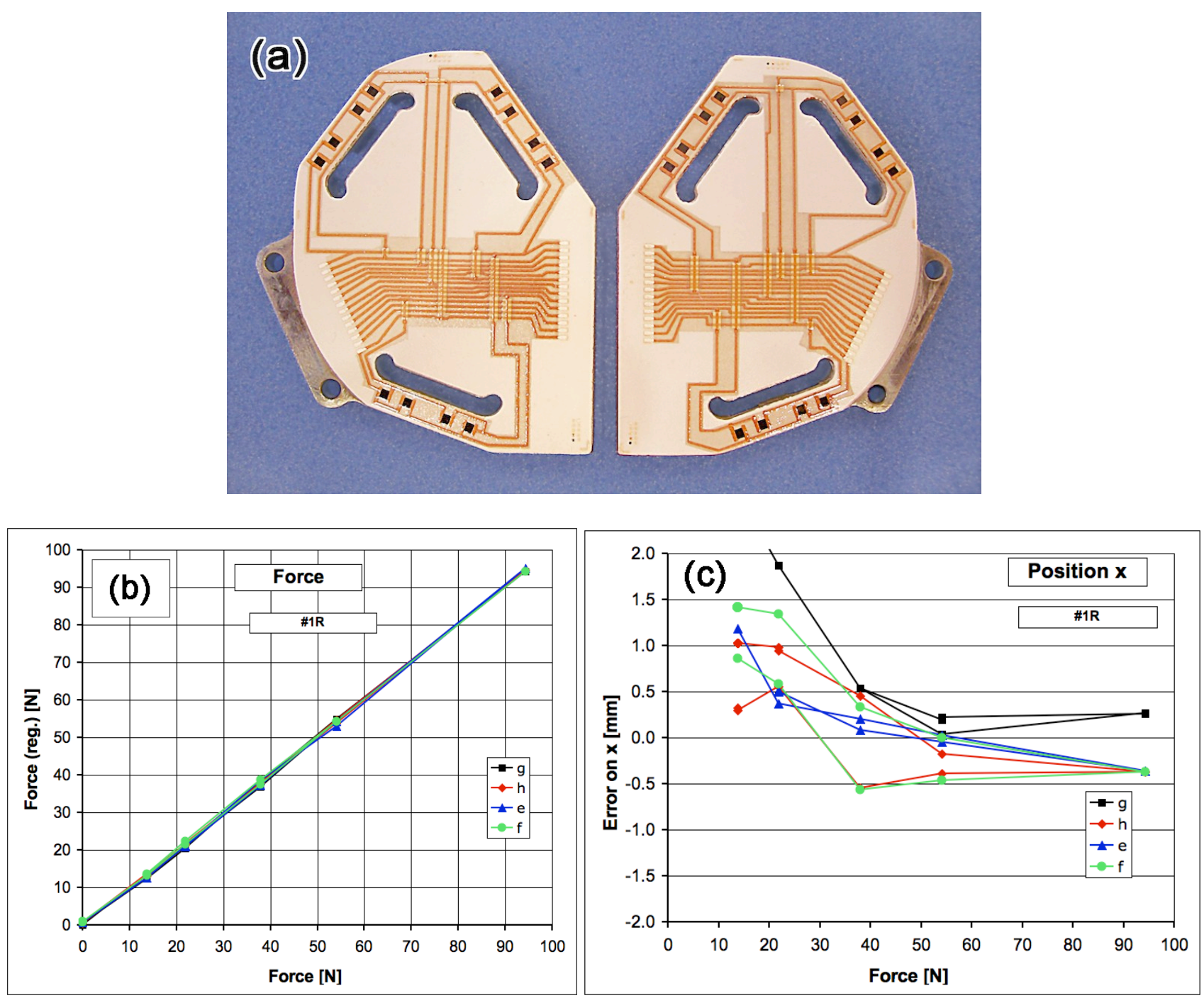

Fig. 2. (a) sensor platforms screen-printed with new low-firing thick-film materials; (b) measured force and (c) $\mathrm{X}$ position error after calibration.

\section{Acknowledgements}

The authors gratefully acknowledge financial support from the Swiss National Science Foundation (SNSF) through the NCCR CO-ME II programme, as well as the help of Mr. Matthias Garcin in preparing the samples, and the supply by the University of Bern ARTORG centre of the mechanical structure and testing jig.

\section{References}

[1] Crottet D, Maeder T, Fritschy D, Bleuler H, Nolte LP, Pappas-IP. Development of a force amplitude- and location-sensing device designed to improve the ligament balancing procedure in TKA, IEEE Trans Biomed Eng 2005;52:1609-11.

[2] Crottet D, Kowal J, Sarfert SA, Maeder T, Bleuler H, Nolte LP, Dürselen L. Ligament balancing in TKA: Evaluation of a force-sensing device and the influence of patellar eversion and ligament release. J Biomech 2007;40:1709-1715.

[3] Jacq C, Lüthi B, Maeder T, Lambercy O, Gassert R. Thick-film multi-DOF force / torque sensor for wrist rehabilitation, Sens Actuators A 2010; doi:10.1016/j.sna.2010.01.014 (in press).

[4] Jacq C, Maeder T, Ryser P, Piezoresistive properties of low-firing temperature thick-films on steel sensors, Proc 4th Int Conf Ceram Interconnect Ceram Microsyst Technol (CICMT), Munich, Germany, 2008;411-6.

[5] Jacq C, Maeder T, Ryser P. Load sensing surgical instruments, J Mater Sci: Mat Med 2009;20:S223-7.

[6] Vionnet-Menot S, Grimaldi C, Maeder T, Ryser P, Strässler S. Tunneling-percolation origin of nonuniversality: Theory and experiments, Phys Rev B 2005;71:064201.

[7] Jacq C, Maeder T, Ryser P. Development of low-firing lead-free thick-film materials on steel alloys for piezoresistive sensor applications, Proc 17th IMAPS Eur Microelectron \& Packaging Conf (EMPC), Rimini, Italy, 2009;P07. 